\title{
Screening in primary health care for undiagnosed tremor in an elderly population in Wales
}

\author{
R J Meara, S Bisarya, J P Hobson
}

Despite the fact that effective, though not entirely satisfactory, treatment exists for both essential tremor and Parkinson's disease, many cases in older subjects remain medically undiagnosed and result in considerable remediable handicap. ${ }^{1-3}$ We report the use in general practice of an adaptation of a screening and alerting questionnaire for Parkinson's disease ${ }^{4}$ used to screen for medically undiagnosed tremors in an elderly population.

\section{Subjects, methods, and results}

A questionnaire (see appendix) was mailed with a covering letter of explanation to a random sample of 200 subjects over the age of 60 years ( 100 male, 100 female) not known to have tremor taken from two general practice lists in a rural and a semi-rural area of north Wales. Subjects who responded positively to the question related to shaking of the limbs were said to have screened positively for tremor. Subjects underwent a simple neurological examination, the diagnosis of Parkinson's disease and essential tremor being based upon agreed clinical diagnostic criteria. Briefly, a diagnosis of Parkinson's disease required the presence of bradykinesia and at least one of the following: muscular rigidity, a 4-6 cycle per second tremor at rest in the upper limb, and postural instability. The diagnosis of essential tremor required the presence in the upper limb of relatively longstanding, bilateral, and persistent postural and/or action tremor in the

University

Department of

Geriatric Medicine,

Glan Clwyd District

General Hospital,

Rhyl, Clwyd LL18 5UJ

R J Meara

$S$ Bisarya

J P Hobson

Correspondence to

Dr J P Hobson.

Accepted for publication December 1996

$(\mathcal{F}$ Epidemiol Community

Health 1997;51:574-575) absence of other abnormal neurological signs.

There was an overall response rate of $168 / 200$ (84\%) from the community sample after three mailings. No significant difference between the age and sex of responders and non-responders was found. A total of $20 / 168$ $(12 \%)$ of the subjects screened positively for tremor and, apart from one subject who refused to be visited, were examined. Examination revealed that 10 subjects $(6 \%)$ had previously undiagnosed essential tremor, one subject had a gait apraxia due to vascular disease, and two subjects ( $1 \%$ ) had previously undiagnosed Parkinson's disease. In $7 / 20$ subjects the reported tremor could not be detected on examination.

\section{Comment}

The postal screening tool detected undiagnosed Parkinson's disease and essential tremor in $1 \%$ and $6 \%$ respectively of elderly subjects in this study. This is similar to the estimated prevalence of these diseases in the elderly based on total census door to door approaches. ${ }^{25}$ Two cases of medically undiagnosed Parkinson's disease were detected by the screening questionnaire; both patients reported tremor and gait disturbance. In the presence of reported tremor, gait abnormality increases the specificity for Parkinson's disease. A positive reply to tremor and gait abnormality has been reported to correctly identify over $90 \%$ of true cases and true negative cases of Parkinson's disease. ${ }^{4}$ The severity of tremor in four out of the 10 subjects with undiagnosed essential tremor was sufficiently disabling to justify consideration of drug treatment. Seven subjects reported tremor that was not confirmed by bedside examination. On further questioning the tremor they reported was not persistent but was episodic and is likely to have represented enhanced physiological tremor. Screening for tremor in community samples of elderly people will detect medical conditions for which treatment exists and will help to identify subjects with possible Parkinson's disease at an earlier stage.

Funding: none

Conflict of interest: none

1 Schoenberg BS, Anderson DW, Haerer AF. Prevalence of Parkinson's disease in the biracial population of Copiah County, Mississippi. Neurology 1985;35:841-5.

2 Morgante L, Rocca WA, Di Rosa AE, et al. Prevalence of Parkinson's disease and other types of Parkinsonism: a door to door survey in three Sicilian municipalities. Neurology 1992;42:1901-7.

3 Busenbark KL, Nash J, Nash S, Hubble JP, Koller WC Is essential tremor benign? Neurology 1991;41:1982-3.

4 Mutch WJ, Smith WC, Scott RF A screening and alerting questionnaire for Parkinsonism. Neuroepidemiology 1991; questionn

5 Rautakorpi I, Takala J, Martilla RJ, Sievers K, Rinne UK Essential tremor in a Finnish population. Acta Neurol Scand 1982;66:58-57. 
Appendix

QUESTIONNAIRE

Please answer the following questions to the best of your knowledge.

Have you suffered any of the following illnesses? Please tick boxes YES or No
1. Arthritis
YES $\square$
NO
2. Stroke
YES
NO
3. Do you take any medication for your nerves?
YES
4. Have you become very forgetful?
5. Have you lost your sense of smell?

If you suffer from any other illnesses not mentioned above, could you please list them below:

The following questions ask if you have any of these problems. Please try and answer all of the questions by placing a tick in the YES or No box.

1. Do your arms or legs ever shake?

$\begin{array}{ll}\text { YES } \square & \text { NO } \square \\ \text { YES } \square & \text { NO } \square \\ \text { YES } \square & \text { NO } \square \\ \text { YES } \square & \text { NO } \square \\ \text { YES } \square & \text { NO } \square \\ \text { YES } \square & \text { NO } \square \\ \text { YES } \square & \text { NO } \square \\ \text { YES } \square & \text { NO } \square \\ \text { YES } \square & \text { NO } \square\end{array}$

2. During the day do your muscles ever feel stiff and aching apart from after exercise?

3. Do you find it difficult to get out of a chair?

4. Do you shuffle when you walk?

5. Have you difficulty turning in bed?

6. Has your writing become smaller?

7. Is it difficult to open jars (other than new), or use a

a screwdriver, or fasten small buttons on your shirt?

8. Do you lose your balance when turning?

Please tick the box if you do not wish further contact from the research team

Thank you for completing this questionnaire, please return it in the envelope provided 